\title{
Mixed Low-Level Radioactive Waste (MLLW) Primer
}

\author{
William E. Schwinkendorf
}

Published April 1999

\section{Idaho National Engineering and Environmental Laboratory National Low-Level Waste Management Program Lockheed Martin Idaho Technologies Company Idaho Falls, Idaho 83415}

Prepared for the

U.S. Department of Energy Assistant Secretary for Environmental Management Under DOE Idaho Operations Office Contract DE-AC07-94ID13223 


\section{DISCLAIMER}

This report was prepared as an account of work sponsored by an agency of the United States Government. Neither the United States Government nor any agency thereof, nor any of their employees, make any warranty, express or implied, or assumes any legal liability or responsibility for the accuracy, completeness, or usefulness of any information, apparatus, product, or process disclosed, or represents that its use would not infringe privately owned rights. Reference herein to any specific commercial product, process, or service by trade name, trademark, manufacturer, or otherwise does not necessarily constitute or imply its endorsement, recommendation, or favoring by the United States Government or any agency thereof. The views and opinions of authors expressed herein do not necessarily state or reflect those of the United States Government or any agency thereof. 


\section{DISCLAIMER}

Portions of this document may be illegible in electronic image products. Images are produced from the best available original document. 


\section{CONTENTS}

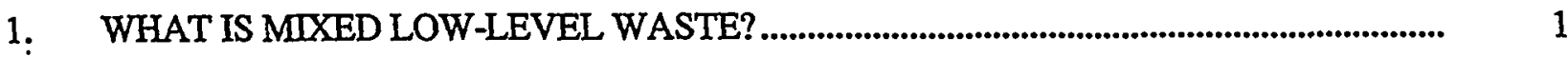

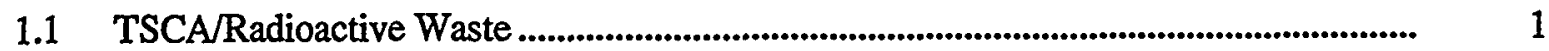

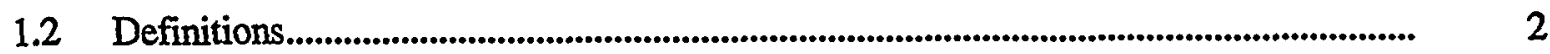

1.2.1 Radioactive Materials ........................................................................................ 2

1.2.2 Hazardous Waste ........................................................................................... 4

THE F LIST: WASTES FROM NONSPECIFIC SOURCES.............................................. 7

THE K LIST: WASTES FROM SPECIFIC SOURCES............................................... 7

THE P AND U LISTS: DISCARDED COMMERCIAL CHEMICAL PRODUCTS ........... 8

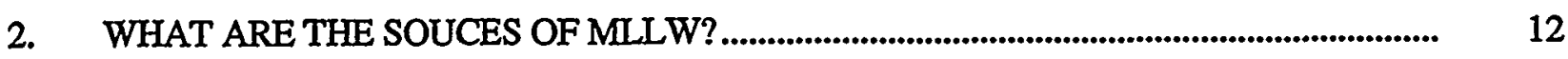

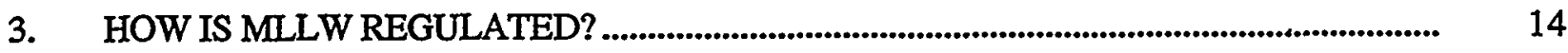

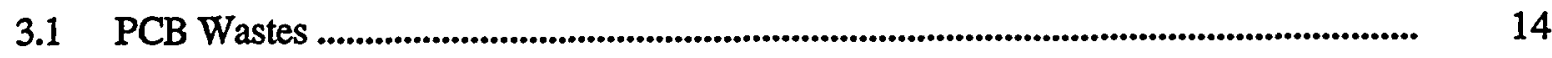

3.2 Introduction to RCRA Hazardous Wastes ................................................................... 15

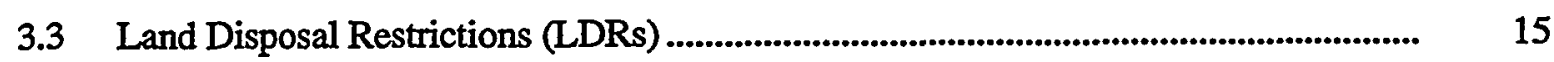

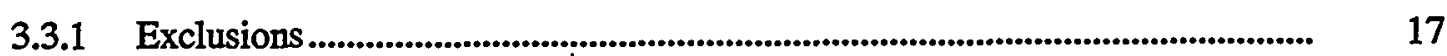

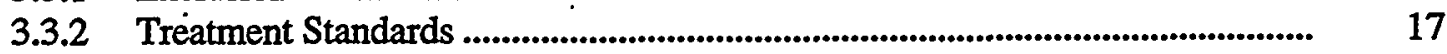

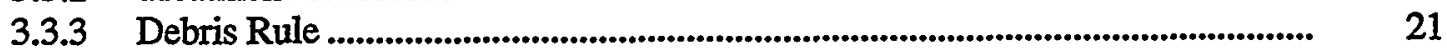

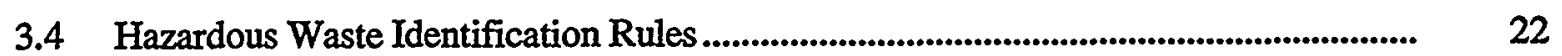

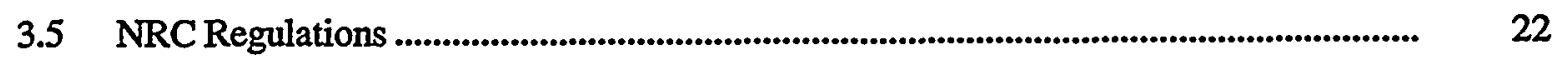

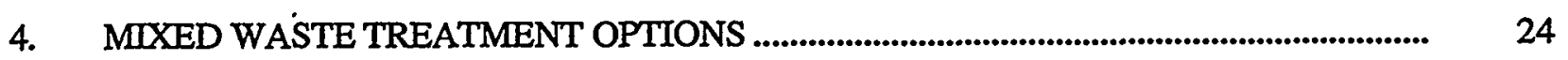

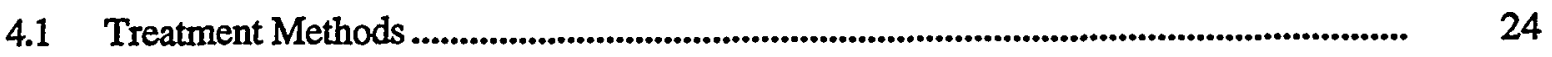

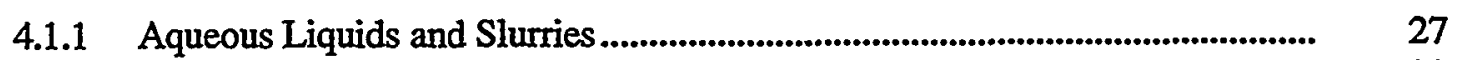

4.1.2 Organic Liquids ........................................................................................... 28

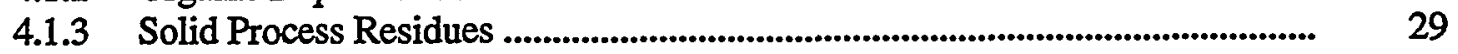

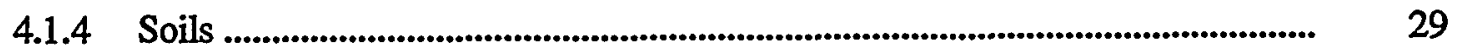

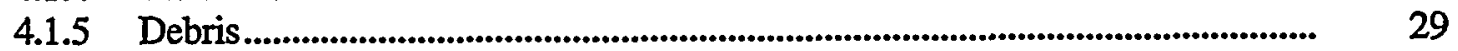

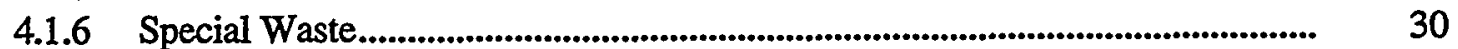

4.1.7 Inherently Hazardous Waste .......................................................................... 30

TABLES

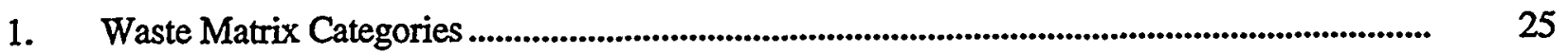

2. Alternative treatment standards for hazardous debris ........................................................ 32 


\section{Mixed Low-Level Radioactive Waste (MLLW) Primer}

\section{WHAT IS MIXED LOW-LEVEL WASTE?}

The term "mixed waste" means waste that contains a hazardous waste component and a radioactive material component. The hazardous waste is identified in the Resource Conservation and Recovery Act (RCRA) and listed under 40 CFR Part 261, Subpart D, and/or exhibits a characteristic described in 40 CFR Part 261, Subpart C. Radioactive material must be classified as source, special nuclear, or by-product material subject to the Atomic Energy Act of 1954 (AEA) (42 U.S.C. Section 201 et seq.).

Mixed waste is jointly regulated by the Department of Energy (DOE), the Nuclear Regulatory Commission (NRC) or.NRC's Agreement States under the AEA, and the Environmental Protection Agency (EPA) or EPA's RCRA Authorized States under RCRA. The AEA regulates the RCRA-exempt radioactive portion (52 FR 15939; May 1, 1987). The NRC or NRC's Agreement States regulate the nuclear portion of mixed wastes from commercial and non-DOE federal facilities, while DOE regulates only the nuclear portion of the waste from DOE facilities. RCRA regulates the hazardous portion of the waste as any other hazardous waste regardless of the source. The State-implemented RCRA programs must establish requirements at least as stringent as the federal EPA requirements, and in some cases, they have established requirements that are more stringent.

Thus, mixed low-level waste is low-level waste that contains a known hazardous waste (i.e., a RCRA listed hazardous waste) or that exhibits one or more of the RCRA hazardous characteristics. For wastes that are not listed in Subpart D of 40 CFR Part 261, testing is not necessarily required to determine whether the low-level wastes exhibits any of the hazardous characteristics. A generator may be able to determine whether that low-level waste is mixed low-level waste based upon knowledge of the waste characteristics or the process that generates the low-level waste.

Furthermore, if the generator normally segregates low-level waste from hazardous and other types of wastes, there is no need to assume that hazardous wastes may have been inadvertently mixed with low-level waste or to inspect each container or receptacle to ensure that inadvertent mixing has not occurred. Although the generator is subject to RCRA inspections and must follow the manifest, pretransport, and other requirements of 40 CFR 262, the generator is not required to demonstrate that every low-level waste container is free of hazardous waste.

Not included in the EPA/NRC definition of mixed waste are certain materials regulated under the Toxic Substances Control Act (TSCA), high-level radioactive waste, spent nuclear fuel, or Naturally Occurring or Accelerator Produced Radioactive Materials (NARM).

\subsection{TSCA/Radioactive Waste}

Although waste contaminated with TSCA regulated materials and low-level radioactive material is not, by the EPA/NRC definition, mixed low-level waste, there are TSCA materials that are also regulated under RCRA.

PCBs are regulated not only under TSCA but are also referenced under RCRA in 40 CFR 261.8 and in the LDRs, 40 CFR 268.42 (liquid PCB waste concentrations greater than $50 \mathrm{ppm}$ ). A medium such as water, soil, debris, etc., contaminated only with PCBs is not a hazardous waste under RCRA unless it is hazardous by virtue of meeting the criteria for being characteristic per 40 CFR 261.21 through 261.24 or 261.31 through 261.33. If it can be determined that the PCB waste is characteristically hazardous, then the next step is to refer to 40 CFR 261.8 , to determine if this waste can be excluded from 
regulation under RCRA, which provides for the exclusion of dielectric fluids containing PCBs if they are hazardous only because they fail toxicity characteristic leaching procedure levels for D018 through D043 constituents. PCB waste that meets these criteria would be regulated under TSCA, not RCRA. It should be noted that states have not been granted TSCA authority. TSCA issues are handled by the PCB Regional Coordinator representing the particular EPA region in which a particular facility or generator is located.

PCB/radioactive waste means PCBs regulated for disposal under 40 CFR 761, Subpart $D$ that also contain source, special nuclear, or by-product material subject to regulation under the AEA, as amended, or NARM. The PCB portion of the waste is regulated by the EPA under TSCA as codified in $40 \mathrm{CFR} 761$. Section 761.50(b)(7) provides that any person disposing of PCB/radioactive waste must do so taking into account both its PCB concentration and its radioactive properties. There are currently no federal regulations covering disposal of NARM with high radioactivity concentrations. However, NARM may be state regulated and the EPA has initiated studies to characterize the radiological hazards posed by NARM more accurately.

When exposed to heat, PCBs create polychlorinated dioxins and dibenzofurans, both highly toxic substances. EPA regulations as set forth in 40 CFR Part 766 deal with the requirements for these substances under TSCA. These regulations impose testing requirements to ascertain whether certain specific chemical substances are contaminated with halogenated dibenzodioxins and halogenated dibenzofurans. Also, $40 \mathrm{CFR} 766.38$ provides reporting requirements for precursor chemicals.

Although dioxins and furans are regulated under TSCA, they are also EPA listed wastes F020, F021, F022, and F023 in 40 CFR 261.31. These materials are also listed in the Universal Treatment Standards in 40 CFR 268.48. Thus, these materials fall under RCRA and, if commingled with radionuclides are treated as mixed waste.

Asbestos is another material regulated under TSCA as well as the National Emission Standards for Hazardous Air Pollutants (NESHAP). The regulations that deal with asbestos include 40 CFR 61 Subpart $M$ and 40 CFR Part 763. These regulations describe EPAs requirements for packaging, transportation and disposal of asbestos. In addition to these Federal requirements, state or local government agencies may require more stringent handling procedures. Since asbestos is not a RCRA hazardous waste, if commingled with radionuclides it may be handled as lowlevel radioactive waste as long as the radioactive disposal facility also meets the requirements for asbestos disposal.

\subsection{Definitions}

\subsubsection{Radioactive Materials}

1.2.1.1 By-Product Material. There are basically two types of by-product materials. The first are produced by a nuclear reactor and the second are produced by the uranium and thorium mining process. A more precise definition reads: "(1) Any radioactive material (except special nuclear material) yielded in, or made radioactive by, exposure incident to the process of producing or using special nuclear material; and (2) The tailings or wastes produced by the extraction or concentration of uranium or thorium from ore processed primarily for its source material content, including discrete surface wastes resulting from uranium solution extraction processes. Underground ore bodies depleted by these solution extraction operations do not constitute 'by-product material' within this definition (10 CFR 20.1003)."

Except for certain ores containing source material, which are defined as source material in 10 CFR 40.4(h), and uranium and thorium mill tailings or wastes, NRC and EPA consider that only the 
radionuclides themselves are exempt from RCRA. Section 1004(27) of RCRA excludes source, special nuclear, and by-product material from the definition of "solid waste." Since "hazardous waste" is a subset of "solid waste," RCRA also excludes source, special nuclear, and by-product materials from the definition of hazardous waste and, therefore, from regulation under EPA's RCRA Subtitle C program.

1.2.1.2 Low-level Waste ( $L L W$ ). LLW includes all radioactive waste other than uranium mill tailings, transuranic waste, high-level waste, and spent nuclear fuel. While most low-level waste is relatively short-lived and has low levels of radioactivity, some present a significant radiation hazard and require special treatment and disposal. Low-level wastes are generated by a wide range of institutions and facilities using radioactive materials, including nuclear power plants, government and defense laboratories and reactors, hospitals, laboratories, and industrial plants. The waste takes a variety of forms, such as medical treatment and research materials, contaminated wiping rags and paper towels, used filters and filter sludge, protective clothing, hand tools, equipment, parts of decommissioned nuclear power plants, and so forth. The radiation from low-level waste is sometimes high enough to require shielding for handling and shipment.

Low-level wastes are classified in three classes, A, B and C, according to the concentration and the radionuclides contained in the waste. These classifications determine the requirements for handling, packaging, shipping, and disposing of LLW.

\subsubsection{Naturally Occurring or Accelerator Produced Radioactive Materials (NARM).}

Radioactive materials not covered under the AEA that are naturally occurring or produced by an accelerator. A subset of NARM is Naturally Occurring Radioactive Material (NORM). NORM refers to materials not covered under the AEA whose radioactivity has been enhanced (radionuclide concentrations are either increased or redistributed where they are more likely to cause exposure to man) usually by mineral extraction or processing activities. Examples are exploration and production wastes from the oil and natural gas industry and phosphate slag piles from the phosphate mining industry. This term is not used to describe or discuss the natural radioactivity of rocks and soils, or background radiation, but instead refers to materials whose radioactivity is technologically enhanced by controllable practices. NARM waste is not covered under the AEA, is not a form of LLW, and is not regulated by NRC.

1.2.1.4 Source Material. Source Material is the uranium or thorium ores mined from the Earth. Source material is defined in 10 CFR 20.1003 as "(1) Uranium, or thorium or any combination of uranium and thorium in any physical or chemical form; or (2) Ores that contain, by weight, one-twentieth of 1 percent ( 0.05 percent), or more, of uranium, thorium, or any combination or uranium and thorium. Source material does not include special nuclear material."

1.2.1.5 Special Nuclear Material (SNM). SNM is defined in 10 CFR 20.1003 as "(1) Plutonium, uranium-233, uranium enriched in the isotope 233 or in isotope 235 , and any other material that the NRC, pursuant to the provisions of section 51 of the AEA, determines to be SNM, but does not include source material; or (2) Any material artificially enriched by any of the foregoing but does not include source material. SNM is important in the fabrication of weapons grade materials and as such has strict licensing and handling controls."

1.2.1.6 Transuranic Waste (TRU). TRU comes primarily from the reprocessing of spent fuel and use of plutonium in the fabrication of nuclear weapons. Transuranic waste is defined by DOE as "waste contaminated with alpha-emitting radionuclides of atomic number greater than 92 (that is, uranium; hence the term transuranic) and half-lives greater than 20 years in concentrations greater than 100 nanocuries per gram." Most transuranic waste remains toxic for centuries and requires the same long-term isolation as high-level waste. All other mixed waste is considered mixed low-level waste. Transuranic mixed waste and mixed low-level wastes may be generated in many forms, including liquids, debris, and soils. 


\subsubsection{Hazardous Waste}

One of the most widely used definitions of hazardous waste is contained in RCRA. The RCRA defines wastes as toxic or hazardous if they "cause or significantly contribute to an increase in mortality or an increase in serious irreversible, or incapacitating reversible illness; or pose a substantial present or potential hazard to human health or the environment when improperly treated, stored, transported, disposed of, or otherwise managed."

For regulatory purposes, EPA has adopted the listing approach to defining hazardous waste, but also prescribed a test procedure such that wastes are identified by one of several lists or by producing characteristic responses when subjected to a test protocol. The RCRA regulations (40 CFR 261 and 262) specify that solid waste is a hazardous waste if it is not excluded from regulation, and meets any of the following conditions:

- Exhibits any of the characteristics of a hazardous waste

- Has been named as a hazardous waste and listed as such in the regulations

- Is a mixture containing a listed hazardous waste and a nonhazardous solid waste

- Is a waste derived from the treatment, storage or disposal of a listed hazardous waste. as follows:

"Solid waste" is defined in detail in 40 CFR 261.2. Section 6903(27) of RCRA defines solid waste

'The term 'solid waste' means any garbage, refuse, sludge from a waste treatment plant, water supply treatment plant, or air pollution control facility and other discarded material, including solid, liquid, semisolid, or contained gaseous material resulting from industrial, commercial, mining, and agricultural operations, and from community activities, but does not include solid or dissolved material in domestic sewage, or solid or dissolved materials in irrigation return flows or industrial discharges which are point sources subject to permits under section 1342 of title 33, or source, special nuclear, or by-product material as defined by the Atomic Energy Act of 1954, as amended (68 Stat. 923) (42 U.S.C. 2011 et seq.)."

The hazardous waste listings and characteristics, and the mixture and derived-from rules are all essential parts of the definition of hazardous waste, but these key elements are all described in different sections of the RCRA regulations. Only 40 CFR 261.3, entitled Definition of Hazardous Waste, unites all four elements to establish the formal definition of hazardous waste. This section also explains in detail the seven regulatory exemptions from the mixture and derived-from rules. Substantive rules about the listings and characteristics are found elsewhere.

1.2.2.1 Characteristic Hazardous Wastes. A hazardous waste characteristic is a measurable property that indicates that a waste poses a sufficient threat to deserve regulation as hazardous. EPA identified four characteristics which, when present in a waste, can cause death or illness in humans or ecological damage. These four characteristics of hazardous waste are:

- Ignitability

- Corrosivity 
- Reactivity

- Toxicity.

EPA also decided that the presence of these characteristics of hazardous waste should be detectable by using a standardized test method or by applying general knowledge of the waste's properties. These characteristics are a necessary supplement to the hazardous waste listings and provide a screening mechanism that waste handlers must apply to all wastes from all industries. In this sense, the characteristics provide a more complete and inclusive means of identifying hazardous wastes than do the hazardous waste listings.

The regulations explaining these characteristics and the test methods to be used in detecting their presence are found in Part 261, Subpart C. Note that although waste handlers can use the test methods referenced in Subpart $C$ to determine whether a waste displays these characteristics, they are not required to do so. In other words, any handler of industrial waste may apply knowledge of the waste's properties to determine if it exhibits a characteristic, instead of sending the waste for expensive laboratory testing. As with listed wastes, characteristic wastes are assigned waste codes. Ignitable, corrosive, and reactive wastes carry the waste codes D001, D002, and D003, respectively. Wastes displaying the characteristic of toxicity can carry any of the waste codes D004 through D043.

1.2.2.1.1 Ignitability-Ignitable wastes are wastes that can readily catch fire and sustain combustion. Many paints, cleaners, and other industrial wastes pose such a fire hazard. Most ignitable wastes are liquid in physical form. A flashpoint test is the method used for determining whether a liquid waste is combustible enough to deserve regulation as hazardous. The flashpoint test determines the lowest temperature at which a chemical ignites when exposed to flame. Many wastes in solid or nonliquid physical form (e.g., wood, paper) can also readily catch fire and sustain combustion, but EPA did not intend to regulate most of these nonliquid materials as ignitable wastes. A nonliquid waste is only hazardous due to ignitability if it can spontaneously catch fire under normal handling conditions and can burn so vigorously that it creates a hazard. Certain compressed gases and chemicals called oxidizers can also be ignitable. Ignitable wastes carry the waste code D001 and are among the most common hazardous wastes. The regulations describing the characteristic of ignitability are codified at 40 CFR 261.21.

1.2.2.1.2 Corrosivity-Corrosive wastes are acidic or alkaline (basic) wastes that can readily corrode or dissolve flesh, metal, or other materials. They are also among the most common hazardous wastestreams. Waste sulfuric acid from automotive batteries is an example of a corrosive waste. Two criteria are used to identify corrosive hazardous wastes. The first is a pH test. Aqueous wastes with a pH greater than or equal to 12.5 or less than or equal to 2 are corrosive under EPA's rules. A waste may also be corrosive if it has the ability to corrode steel in a specific EPA-approved test protocol. Corrosive wastes carry the waste code D002. The regulations describing the corrosivity characteristic are found at 40 CFR 261.22.

1.2.2.1.3 Reactivity-A reactive waste is one that readily explodes or undergoes violent reactions. Common examples are discarded munitions or explosives. In many cases, there is no reliable test method to evaluate a waste's potential to explode or react violently under common handling conditions. Therefore, EPA uses narrative criteria to define most reactive wastes and allows waste handlers to use their best judgment in determining if a waste is sufficiently reactive to be regulated. This is possible because reactive hazardous wastes are relatively uncommon and the dangers they pose are well known to the few waste handlers who deal with them. A waste is reactive if it meets any of the following criteria:

- It can explode or violently react when exposed to water or under normal handling conditions 
- It can create toxic fumes or gases when exposed to water or under common handling conditions

- It meets the criteria for classification as an explosive under Department of Transportation rules.

Wastes exhibiting the characteristic of reactivity are assigned the waste code D003. The reactivity characteristic is described in the regulations at 40 CFT 261.23.

1.2.2.1.4 Toxicity Characteristic-The leaching of toxic compounds or elements into groundwater drinking supplies from wastes disposed of in landfills is one of the most common ways the general population can be exposed to the chemicals found in industrial wastes. This characteristic is designed to identify wastes likely to leach dangerous concentrations of certain known toxic chemicals into groundwater. To predict whether any particular waste is likely to leach chemicals into groundwater in the absence of special restrictions on its handling, a laboratory procedure was designed that replicates the leaching process and other effects that occur when wastes are buried in a typical municipal landfill. This laboratory procedure is known as the toxicity characteristic leaching procedure (TCLP). Using the TCLP on a waste sample creates a liquid leachate that is similar to the liquid EPA would expect to find in the ground near a landfill containing the same waste. Once the leachate is created in the laboratory, the analyst must determine whether it contains any of 39 different toxic chemicals above specified regulatory levels listed in Table 1 of 40 CFR 261.24. If the leachate sample contains a sufficient concentration of any one or more of the specified chemicals, the waste exhibits the toxicity characteristic (TC) and carries the waste code associated with the compound or element that exceeded the regulatory level. The regulations describing the characteristic of toxicity are codified at 40 CFR 261.24.

1.2.2.2 Listed Hazardous Wastes. EPA has studied and listed as hazardous hundreds of specific industrial waste stream. These wastes are described or listed on four different lists, which are found in the regulations at 40 CFR 261, Subpart D. These four lists are:

- The $\mathrm{F}$ list - The $\mathrm{F}$ list designates as hazardous particular wastes from certain common industrial or manufacturing processes. Because the processes producing these wastes can occur in different sectors of industry, the $\mathrm{F}$ list wastes are known as wastes from nonspecific sources. The F list is codified in the regulations at Section 261.31.

- The $\mathrm{K}$ list - The $\mathrm{K}$ list designates as hazardous particular wastestreams from certain specific industries. $\mathrm{K}$ list wastes are known as wastes from specific sources. The $\mathrm{K}$ list is found at Section 261.32 .

- The $P$ list and the $U$ list - These two lists are similar in that both list as hazardous pure or commercial grade formulations of certain specific unused chemicals. Both the $P$ list and $U$ list are codified in Section 261.33.

These four lists each designate anywhere from 30 to a few hundred wastestreams as hazardous. Each waste on the lists is assigned a waste code consisting of the letter associated with the list followed by three numbers. These waste codes are an important part of the RCRA regulatory system. Assigning the correct waste code to a waste has important implications for the management standards that apply to the waste.

To indicate its reason for listing a waste, EPA assigns a hazard code to each waste listed on the F, $\mathrm{K}, \mathrm{P}$, and $\mathrm{U}$ lists. These hazard codes are listed below. The last four hazard codes apply to wastes that 
have been listed because they typically exhibit one of the four regulatory characteristics of hazardous waste. The hazard codes indicating the basis for listing a waste are:

- Toxic Waste

- Acute Hazardous Waste

- Ignitable Waste

- Corrosive Waste

- $\quad$ Reactive Waste

- Toxicity Characteristic Waste
(T)

(E)

The hazard codes assigned to listed wastes affect the regulations that apply to handling the waste. For instance, acute hazardous wastes accompanied by the hazard code $(\mathrm{H})$ are subject to stricter management standards than most other wastes.

\section{THE F LIST: WASTES FROM NONSPECIFIC SOURCES}

The $F$ list designates as hazardous particular wastestreams from certain common industrial or manufacturing processes. F list wastes usually consist of chemicals that have been used for their intended purpose in an industrial process. That is why $F$ list wastes are known as "manufacturing process wastes." The F list wastes can be divided into seven groups, depending on the type of manufacturing or industrial operation, which creates them. The seven categories of F-listed wastes are:

1. Spent solvent wastes (F001 - F005)

2. Wastes from electroplating and other metal finishing operations (F006-F012, F019)

3. Dioxin-bearing wastes (F020 - F023 and F026 - F028)

4. Wastes from the production of certain chlorinated aliphatic hydrocarbons (F024, F025)

5. Wastes from wood preserving (F032, F034, and F035)

6. Petroleum refinery wastewater treatment sludges (F037 and F038)

7. Multisource leachate (F039).

\section{THE K LIST: WASTES FROM SPECIFIC SOURCES}

The $\mathrm{K}$ list of hazardous wastes designates particular wastes from specific sectors of industry and manufacturing as hazardous. The $\mathrm{K}$ list wastes are therefore known as wastes from specific sources. Like $\mathrm{F}$ list wastes, $\mathrm{K}$ list wastes are manufacturing process wastes. They contain chemicals that have been used for their intended purpose. To determine whether a waste qualifies as K-listed, two primary questions must be answered. First, is the facility that created the waste within one of the 17 different industrial or manufacturing categories on the $\mathrm{K}$ list? Second, does the waste match one of the specific $\mathrm{K}$ list waste descriptions? The 17 industries that can generate $\mathrm{K}$ list wastes are: 
1. Wood preservation

2. Inorganic pigment manufacturing

3. Organic chemicals manufacturing

4. Inorganic chemicals manufacturing

5. Pesticides manufacturing

6. Explosives manufacturing

7. Petroleum refining

8. Iron and steel production

9. Primary copper production

10. Primary lead production

11. Primary zinc production

12. Primary aluminum production

13. Ferroalloys production

14. Secondary lead processing

15. Veterinary pharmaceuticals manufacturing

16. Ink formulation

17. Coking (processing of coal to produce coke, a material used in iron and steel production).

In general, the $\mathrm{K}$ listings target much more specific waste streams than the $\mathrm{F}$ listings. Industries that generate $\mathrm{K}$-listed wastes, such as the wood preserving and petroleum refining industries, can also generate $\mathrm{F}$-listed wastes. Typically, $\mathrm{K}$ listings describe more specific waste streams than $\mathrm{F}$ listings applicable to the same industry.

\section{THE P AND U LISTS: DISCARDED COMMERCIAL CHEMICAL PRODUCTS}

The $P$ and $U$ lists designate as hazardous pure or commercial grade formulations of certain unused chemicals. For a waste to qualify as P- or U-listed, a waste must meet the following three criteria:

1. The waste must contain one of the chemicals listed on the $\mathrm{P}$ or $\mathrm{U}$ list.

2. The chemical in the waste must be unused.

3. The chemical in the waste must be in the form of a "commercial chemical product," as EPA defines that term. 
1.2.2.3 Mixture and Derived-From Rules. The mixture and derived-from rules operate differently for listed waste and characteristic wastes. The mixture rule for listed wastes states that a mixture made up of any amount of a nonhazardous solid waste and any amount of a listed hazardous waste is considered a listed hazardous waste. In other words, if a small vial of listed waste is mixed with a large quantity of nonhazardous waste, the resulting mixture bears the same waste code and regulatory status as the original listed component of the mixture. This principle applies regardless of the actual health threat posed by the waste mixture or the mixture's chemical composition.

The derived-from rule governs the regulatory status of materials that are created by treating or changing a hazardous waste in some way. For example, ash created by burning a hazardous waste is considered "derived-from" that hazardous waste. The derived-from rule for listed wastes states that any material derived from a listed hazardous waste is also a listed hazardous waste. Thus, ash produced by burning a listed hazardous waste bears that same waste code and regulatory status as the original listed waste, regardless of the ash's actual properties.

The net effect of the mixture and derived-from rules for listed wastes can be summarized as follows: once a waste matches a listing description, it is forever a listed hazardous waste, regardless of how it is mixed, treated, or otherwise changed. Furthermore, any material that comes in contact with the listed waste will also be considered listed, regardless of its chemical composition.

For characteristic wastes, mixture involving characteristic wastes is hazardous only if the mixture itself exhibits a characteristic. Similarly, treatment residues and materials derived from characteristic wastes are hazardous only if they themselves exhibit a characteristic. Unlike listed hazardous wastes, characteristic wastes are hazardous because they possess one of four unique and measurable properties. EPA decided that once a characteristic waste no longer exhibits one of these four dangerous properties, it no longer deserves regulation as hazardous. Thus, a characteristic waste can be made nonhazardous by treating it to remove its hazardous property; however, the Land Disposal Restrictions (40 CFR 268) place certain restrictions on the manner in which a waste can be treated.

There are a few situations in which EPA does not require strict application of the mixture and derived-from rules. Certain mixtures involving listed wastes and certain residues from the treatment of listed wastes typically do not pose enough of a health or environmental threat to deserve regulation as listed wastes. There are three exemptions from the mixture rule and four exemptions from the derivedfrom rule.

- Mixture Rule Exemption

1. If a hazardous waste listed only for a characteristic is mixed with a solid waste, the original listing does not carry through to the resulting mixture if that mixture does not exhibit any hazardous waste characteristics. However, the Agency places certain controls on how hazardous wastes can be treated or mixed with other wastes for the land disposal restrictions. Any hazardous waste mixing must be consistent with these rules.

2. Situations where relatively small quantities of listed hazardous wastes are routed to large-volume wastewater treatment systems. To qualify for this exemption, the amount of listed waste introduced into a wastewater treatment system must be very small (or de minimis) relative to the total amount of wastewater treated in the system, and the wastewater system must be regulated under the Clean Water Act. 
3. The third exemption applies to mixtures involving characteristic wastes and specific mining wastes. This narrow exemption allows certain mixtures to qualify as nonhazardous wastes, even if the mixtures exhibit one or more hazardous waste characteristics.

- Derived-From Rule Exemption

1. Materials that are reclaimed from hazardous waste and used beneficially.

2. The other three exemptions from the derived-from rule apply to residues from the treatment of specific wastes using very specific treatment processes that cause the resulting material to no longer poses enough of a threat to warrant hazardous waste regulation

1.2.2.4 Delisting. The RCRA regulations provide another form of relief from the mixture and derived-from rule principles for listed hazardous wastes. Through a site-specific process known as "delisting," a waste handler can submit to EPA a petition demonstrating that while a particular wastestream generated at their facility may meet a hazardous waste listing description, it does not pose sufficient hazard to deserve RCRA regulation. If EPA grants such a petition, the particular wastestream at that facility will not be regulated as a listed hazardous waste. However, the delisting process demands extensive sampling and analysis, submission of a formal petition, and a complete rulemaking.by EPA. Because the delisting process is difficult, time-consuming, and expensive, it is not considered a readily available exception to the mixture and derived-from rules.

1.2.2.5 Contained-In Policy. The contained-in policy is a special, more flexible version of the mixture and derived-from rules that applies to environmental media and debris contaminated with hazardous waste. Environmental media describes soil, sediments, and groundwater. Debris describes a broad category of larger manufactured and naturally occurring objects that are commonly discarded.

Environmental media are usually contaminated through accidental spills of hazardous waste or spills of product chemicals which, when spilled, become hazardous wastes. Debris can also be contaminated through spills. Most debris in the form of industrial equipment and personal protective gear becomes contaminated with waste or product chemicals during normal industrial operations. Contaminated media and debris are primary examples of "remediation wastes." In other words, they are not wastestreams created during normal industrial or manufacturing operations. They are typically created during cleanups of contaminated sites and during the decommissioning of factories. Handlers of contaminated media and debris usually cannot control or predict the composition of these materials, which have become contaminated though accidents or past negligence.

The hazardous waste identification principles, including the mixture and derived-from rules, apply to as-generated industrial wastes. However, a more flexible version of these principles applies to the primary remediation wastes: environmental media and debris. Although EPA requires that any medium and debris contaminated with a listed waste or exhibiting a hazardous characteristic be regulated like any other hazardous waste, media and debris contaminated with listed hazardous wastes can lose their listed status and become nonhazardous. This occurs only after a demonstration that the particular medium or debris in question no longer poses a sufficient health threat to deserve RCRA regulation. Once the demonstration is made, the medium or debris in question is no longer considered to "contain" a listed hazardous waste and is no longer regulated.

The contained-in policy for environmental media is not actually codified in the RCRA regulations. In legal terms, it is merely a special interpretation of the applicability of the mixture and derived-from 
rules to soil and groundwater that has been upheld in federal court. These principles for the management of contaminated media are therefore known as a policy instead of a rule.

The terms of the contained-in policy are relatively general. Although handlers of listed media must obtain EPA's concurrence that media no longer poses a sufficient health threat to deserve RCRA regulation, the current contained-in policy provides no guidelines on how this demonstration to EPA should be made. However, a determination that an environmental medium no longer contains a listed hazardous waste can be granted on a site-specific basis by EPA officials without any regulatory procedure. Thus, the contained-in policy is a far easier option for eliminating unwarranted hazardous waste regulation for low-risk listed wastes than the process of delisting a hazardous waste.

Debris contaminated with hazardous waste has traditionally been governed by the same nonregulatory contained-in policy explained above. In 1992, EPA codified certain aspects of the contained-in policy for debris in the definition of hazardous waste regulations at 40 CFR 261.3. In particular, EPA included a regulatory passage that explains the process by which handlers of debris contaminated with listed hazardous waste can demonstrate that the debris is nonhazardous. This passage also references certain treatment technologies for decontaminating listed debris so that it no longer contains a listed waste. Thus, the term contained-in policy is now something of a misnomer for contaminated debris, since a contained-in rule for debris, commonly called the debris-rule, now exists. 


\section{WHAT ARE THE SOUCES OF MLLW?}

Commercially generated MLLW is generated in all 50 states and the District of Columbia at nuclear power plants, fuel cycle facilities, pharmaceutical companies, medical and research laboratories, universities and academic institutions, and other facilities. Radioactive and hazardous materials are used in a number of processes such as medical diagnostic testing and research, pharmaceutical and biotechnology development, pesticide research, as well as nuclear power plant operations.

Two primary sources of data are available on commercial generation and management practices. The first is a database developed for the National Profile on Commercially Generated Low-Level Radioactive Mixed Waste (NUREG/CR 5938), a survey of commercial generators jointly sponsored by NRC and EPA that was published in December 1992. The second is a database developed by the Edison Electric Institute from a survey of nuclear power plants in 1997.

The National Profile on Commercially Generated Low-Level Mixed Waste was a joint survey conducted by DOE's Oak Ridge National Laboratory for EPA and NRC that identified several examples of mixed low-level waste among the $140,000 \mathrm{ft}^{3}$ generated in 1990. Among them are:

- $\quad$ Liquid scintillation cocktails (LSC). $\left(100,000 \mathrm{ft}^{3}, 71 \%\right.$ of total)

- Organic solvents such as chlorofluorocarbons (CFCs), corrosive organics, and waste oil $(25,200 \mathrm{ft} 3,18 \%$ of total $)$

- Toxic metals such as discarded lead shielding $\left(4,200 \mathrm{ft}^{3}\right.$, or $3 \%$ of total)

- Other waste streams consisting of complex waste streams comprised of more than one component $\left(11,200 \mathrm{ft}^{3}\right.$, or $8 \%$ of total)

This survey indicates that potential commercial mixed low-level waste comprises a small percentage of all low-level waste, whereas DOE is the source of over $90 \%$ of all mixed waste in this country.

The industrial category generated the most mixed waste in 1990 , approximately $50,000 \mathrm{ft}^{3}$. The predominant waste stream reported by this generator category was LSC (68\%) followed by the "other" waste stream (14\%). The Industrial category included facilities such as radiopharmaceutical, chemical, nuclear fuel, and sealed source manufacturers; industrial research and development companies; and consulting firms and analytical laboratories.

The nuclear utility category produced the least amount of mixed waste, approximately $14,000 \mathrm{ft}^{3}$. The predominant waste streams in this generator category were waste oil (35\%) followed by CFCs (27\%) and the "other" category (17\%). Based on the results of the National Profile, the nuclear utilities produced only $11 \mathrm{ft}^{3}$ of LSC in 1990.

The Academic category produced approximately $29,000 \mathrm{ft}^{3}$ (92\% LSC, $4 \%$ "other"). The Government (non-DOE) category produced approximately $27,000 \mathrm{ft}^{3}$ (77\% LSC, $13 \%$ "other organics" i.e., those organic compounds not included in the CFC or chlorinated organics category). The Medical category produced approximately $20,000 \mathrm{ft}^{3}$ (94\% LSC, $3 \%$ other organics). The predominant radionuclides reported by the respondents to the survey, although not necessarily in their order of predominance, were ${ }^{14} \mathrm{C},{ }^{3} \mathrm{H},{ }^{32} \mathrm{P},{ }^{35} \mathrm{~S},{ }^{60} \mathrm{Co},{ }^{125} \mathrm{I},{ }^{137} \mathrm{Cs},{ }^{134} \mathrm{Cs},{ }^{238} \mathrm{U}$, and ${ }^{51} \mathrm{Cr}$. 
. The Edison Electric Institute, based on the 1997 survey of nuclear power plants, reported that the volume of MLLW generated by the nuclear utility industry was substantially reduced from 1990 levels due to waste minimization practices being followed by the generators. Legacy MLLW was also reduced due to limited treatment technology development. Based on the Mixed Waste Treatment Study prepared for the Electric Power Research Institute (December 1995), for nuclear utilities there are still a few mixed wastes for which treatment technologies or disposal facilities may not be commercially available. Wastes, such as freon still bottoms, lead paint chips and sludge are being indefinitely stored due to the lack of treatment and disposal facilities. EPA site visits to hospitals and universities in 1998 found a small number of mixed wastes that could not be treated with technologies that are commercially available at this time. In addition, industry groups such as the American Chemical Society, and the International Isotope Society, have identified difficulty finding suitable treatment and/or disposal for some of the mixed wastes they generate despite efforts to minimize waste generation in general and mixed waste generation in particular. They also cite very high costs for the treatment and disposal that is available.

Under the 1984 Amendments to RCRA, Land Disposal Restriction (LDR) regulations prohibit disposal of most mixed waste including LLMW until it meets specific treatment standards. While most of the commercial mixed waste that is generated and stored can be treated to meet the LDR's by commercially-available treatment technology, there still exists a small percentage of commercial mixed waste for which no treatment or disposal capacity is available. 


\section{HOW IS MLLW REGULATED?}

Mixed waste is hazardous waste and consequently subject to RCRA hazardous waste regulations, including the land disposal restrictions, regardless of the type of radioactive element contained therein. Treatment standards for hazardous wastes are found in Section 268.40 of the RCRA regulations. In some cases special treatment standards are listed for mixed wastes, such as for radioactive lead solids (D008) and elemental mercury contaminated with radioactive materials (D009). When no special standards are listed, the normal treatment standards for the particular waste code apply (55 FR 22644; June 1, 1990).

RCRA specifies that the best demonstrated available technology (BDAT) should be used to meet the land disposal restrictions. While treatment of mixed waste is required to reduce the toxicity of the waste or to immobilize hazardous constituents, the radionuclides present in the mixed waste require special consideration. Mixed waste must be managed according to both its radioactive and hazardous characteristics.

Section 1006 of the RCRA statute provides that if application of both RCRA and AEA regulations creates a conflict, the AEA regulation would take precedence to the extent of the inconsistency between the regulations (OSWER Directive 9541.00-6; also 52 FR 15940; May 1, 1987).

\subsection{PCB Wastes}

In general, PCBs with a concentration of $50 \mathrm{ppm}$ or greater must be disposed of in an incinerator, in compliance with the provisions of 40 CFR 761.70. Under 40 CFR 761.60(e), requests for alternate methods of PCB destruction that will result in a level of performance equivalent to the provisions of 40 CFR 761.70 may be submitted to the Administrator for consideration. The applicable Regional EPA Administrator will be contacted for alternate methods to be used in one EPA region only. The Director, Exposure Evaluation Division, will be contacted to request alternate disposal methods that will be used in more than one region.

Liquid PCBs at a concentration greater than 50 ppm, but less than 500 ppm may be disposed of in an incinerator, a chemical waste landfill that complies with the requirements of 40 CFR 761.75 , or a high-efficiency boiler, according to 40 CFR 761.60. Nonliquid PCBs at a concentration greater than 50 $\mathrm{ppm}$ in the form of contaminated soil, rags, or debris may be disposed of in an incinerator or a chemical waste landfill that complies with 40 CFR 761.75.

PCBs are regulated not only under TSCA, but are also referenced under RCRA in 40 CFR 261.8 and in the LDRs, 40 CFR 268.42 (liquid PCB waste concentrations greater than $50 \mathrm{ppm}$ ). A medium such as water, soil, debris, etc., contaminated only with PCBs is not a hazardous waste under RCRA unless it is hazardous by virtue of meeting the criteria for being characteristic per 40 CFR 261.21 through 261.24 or 261.31 through 261.33. If it can be determined that the PCB waste is characteristically hazardous, then the next step is to refer to 40 CFR 261.8, to determine if this waste can be excluded from regulation under RCRA, which provides for the exclusion of dielectric fluids containing PCBs if they are hazardous only because they fail TCLP levels for D018 through D043 constituents. PCB waste that meets these criteria would be regulated under TSCA, not RCRA.

Assuming that the PCB waste still meets the criteria for being regulated under RCRA, then the LDRs become an issue. Under the RCRA LDRs, liquid PCB wastes with a PCB concentration greater than $50 \mathrm{ppm}$ are prohibited from land disposal. Referring back to the TSCA regulations, 40 CFR 761.1(e) states that the PCB regulations in Part 761 do not preempt other more stringent federal statutes and regulations. Therefore, although 40 CFR 761.60 states that liquid PCB wastes may be land disposed in a 
chemical waste landfill, it is possible that the EPA Regional.Administrator will take the more stringent RCRA position that all PCB waste will be incinerated or otherwise thermally treated.

TSCA has an antidilution rule (40 CFR 761.1b) that states that "no provision specifying a PCB concentration may be avoided as a result of any dilution, unless otherwise specifically provided." This means that if dielectric fluid containing $80 \mathrm{ppm}$ PCBs is spilled on the ground, the soil is considered to have a PCB concentration of $80 \mathrm{ppm}$ based on the original concentration of material spilled, even though the actual concentration of PCBs in the soil may be significantly less. This rule applies specifically to new spills and does not apply to remediation waste where the actual concentration in the media is used for regulatory purposes.

\subsection{Introduction to RCRA Hazardous Wastes}

The primary goal of the RCRA Subtitle $C$ program is to protect human health and the environment from the dangers associated with generation, transportation, treatment, storage, and disposal of hazardous waste. Disposal of hazardous waste on the land is a practice of particular concern to the RCRA program. Land disposal units, such as landfills and surface impoundments, must comply with stringent requirements for liners, leak detection systems, and groundwater monitoring. The land disposal restrictions (LDR) provide a second measure of protection from threats posed by hazardous waste disposal. LDR provides that a hazardous waste cannot be placed on the land until the waste is treated (or meets specific treatment standards) to reduce the mobility or toxicity of the hazardous constituents in the waste.

Waste treated in accordance with treatment standards set by EPA under Section 3004(m) of RCRA are not subject to the prohibitions and may be land disposed. The statute requires EPA to set "levels or methods of treatment, if any, which substantially diminish the toxicity of the waste or substantially reduce the likelihood of migration of hazardous constituents from the waste so that short-term and long-term threats to human health and the environment are minimized." (RCRA Section 3004(m)(1).

Thus, the LDR program found at 40 CFR Part 268 requires that a hazardous waste must be treated (or meet specified levels for hazardous constituents) before disposed of on the land. This is called the disposal prohibition. Each waste code has one or more specific treatment standards listed in Part 268, Subpart D. Treatment standards are expressed as either required technologies that must be applied to the waste or contaminant concentration levels that must be met. Treatment standards are based on the performance of the BDAT that is able to substantially diminish the toxicity of a waste or to reduce the mobility of the hazardous constituents in a hazardous waste. Wastes that do not meet treatment standards cannot be "land disposed" unless EPA has granted a variance, extension, or exclusion (or the waste is managed in a "no-migration unit"). In addition to the disposal prohibition, there are prohibitions and limits in the LDR program regarding the dilution and storage of wastes. The program also includes tracking and recordkeeping requirements.

\subsection{Land Disposal Restrictions (LDRs)}

A large part of the hazardous waste management regulatory program, including the LDR program, is designed to protect groundwater. Congress understood that hazardous waste could be made less dangerous to groundwater in two main ways: by reducing a waste's toxicity through destruction or removal of harmful contaminants, or by reducing a waste's leachability by immobilizing hazardous contaminants. When directing EPA to establish the LDR program in RCRA Section 3004(m), Congress specified that EPA should "promulgate regulations specifying those levels or methods of treatment, if any, which substantially diminish the toxicity of the waste or substantially reduce the likelihood of migration of hazardous constituents from the waste." To implement that goal, Congress gave EPA very 
specific directions for establishing the LDR program. In particular, Congress required that EPA specify how hazardous wastes should be treated to satisfy LDR's goal of groundwater protection. The rules EPA promulgated governing how different hazardous wastes must be treated are known as treatment standards, which are instructions on how a hazardous waste should be treated.

Hazardous waste can pollute groundwater through the process known as leaching, in which precipitation percolating through the ground draws contaminants out of buried waste and carries them into groundwater. Placing barriers between wastes and underground water sources is one way to prevent migration of hazardous contaminants into groundwater. Thus, many RCRA regulations focus on requiring hazardous waste containment. For example, RCRA regulations require installation of impermeable liners beneath hazardous waste landfills. Such barriers separate vulnerable groundwater from hazardous constituents likely to leach from the buried wastes.

The land disposal restrictions are based on a different groundwater protection principle. Instead of requiring barriers between groundwater and hazardous wastes, LDR requires that hazardous wastes undergo fundamental physical or chemical changes so that they pose less of a threat to groundwater. For example, many of the chemicals capable of contaminating groundwater are organic compounds. Incineration or burning can destroy these organic compounds, usually breaking them down into less dangerous by-products like carbon dioxide and water. Thus, incineration of organic-bearing hazardous wastes can protect groundwater by destroying organic contaminants before they have a chance to enter underground water supplies. The obvious advantage of such hazardous waste treatment is that it provides a more permanent and lasting form of groundwater protection than does simple hazardous waste containment. Structural barriers separating hazardous contaminants from groundwater can eventually break down or leak. In contrast, treatment that simply destroys harmful contaminants or reduces a waste's toxicity before it enters the environment is a permanent solution to groundwater protection.

Not all types of contaminants found in hazardous wastes can be destroyed. In particular, metal elements are common toxic contaminants that cannot be broken down through combustion. Treatment techniques other than incineration, however, can be used for such wastes. For example, stabilization or immobilization can chemically or physically bind metal contaminants into the wastes that contain them. Although this process does not reduce the overall concentration of toxic metals in a hazardous waste, it does immobilize these constituents, making them less likely to leach from the waste. Reducing the mobility or leachability of hazardous constituents in a waste is thus another means of permanently achieving LDR's groundwater protection goal.

To be subject to the land disposal restrictions, a waste must first be a RCRA hazardous waste. Unless a waste meets the definition of a solid and hazardous waste, its disposal cannot be subject to the LDR program.

Once listed or identified, a hazardous waste becomes restricted, or subject to LDR, when the Agency establishes treatment standards that the waste must meet before it can be land disposed. RCRA Section 3004(g) requires that EPA restrict hazardous wastes from land disposal within 6 months of promulgating a new listing or characteristic. Until the Agency establishes a treatment level, newly listed or identified wastes are not subject to LDR and they may continue to be land disposed. Once EPA promulgates final treatment requirements specifically restricting a waste, however, handlers must manage it in accordance with all the requirements of Part 268 and the waste cannot be land disposed until it meets the treatment level.

The LDR regulations currently apply to all hazardous waste, including mixed waste, listed or identified as of November 8, 1984, under RCRA 3001. They also apply to several hazardous wastes newly listed after November 8, 1984, for which treatment standards have been developed. EPA deferred 
issuing treatment standards for radioactive waste mixed with scheduled hazardous waste until the promulgation of the last scheduled LDR rule on May 8, 1990 (the so-called Third Third rule). Mixed wastes are now subject to LDR regulations.

The land disposal restrictions (LDR) in 40 CFR Part 268 require that hazardous waste prohibited from land disposal meet treatment standards before it is placed in a landfill. A prohibited characteristic waste that has been treated to meet LDR standards (and to eliminate the characteristic) may exit Subtitle $C$ hazardous waste regulation and be sent to a Subtitle $D$ facility, provided the generator sends a one-time notification and certification to the EPA Region or authorized state (Section 268.9(d)). The one-time notification and certification verifies that the waste has been treated to meet all applicable LDR standards and indicates the site of ultimate disposal since the waste is no longer subject to Subtitle C regulation. RCRA Section 4004 specifically prohibits the open dumping of solid waste. If an AEA landfill meets the Subtitle D criteria under 40 CFR Parts 257 or 258, which distinguish between sanitary landfills and open dumps, then the decharacterized mixed waste may be sent to that facility.

\subsubsection{Exclusions}

While the LDR program generally applies to all persons who generate, transport, treat, store, or dispose of a restricted hazardous waste, there are exclusions to the applicability of Part 268. The following hazardous wastes are not subject to the requirements of LDR (Section 268.1(e)):

- Waste generated by conditionally exempt small quantity generators as defined at Section 261.5

- Waste pesticide and container residues disposed of by farmers on their own land pursuant to Section 262.70

- Newly identified or listed hazardous wastes for which EPA has yet to promulgate land disposal treatment standards

- Certain low volume releases, known as de minimis losses, or laboratory chemicals that are mixed with a facility's wastewater and are discharged under the regulation of the Clean Water Act (CWA).

Wastes meeting any of these descriptions may continue to be land disposed without being subject to the LDR program. Other restricted hazardous wastes must be managed in compliance with all requirements of Part 268, unless explicitly exempted by another part of the RCRA program.

\subsubsection{Treatment Standards}

LDR requires that a hazardous waste be adequately treated to fundamentally change the threat posed by the waste before it is land disposed. Waste-specific restrictions are manifested as thresholds for adequate treatment, known as treatment standards. These treatment standards can be expressed as either numeric concentration levels for hazardous constituents, or as a required technology. Once a waste has been restricted and issued a treatment standard, a waste may be land disposed only after it meets the appropriate treatment standard.

The treatment standards for hazardous wastes were originally presented in multiple tables, but a single consolidated table has replaced them. If a waste has been restricted from land disposal, the treatment standard for both wastewaters and nonwastewaters can be found in 40 CFR 268.40. There are three types of treatment standards: 
1. Treatment standards expressed as specified technologies and represented by a five-letter code (described in Section 268.42)

2. Constituent concentrations in an extract of the waste expressed in $\mathrm{mg} / \mathrm{L}$

3. Constituent concentrations in $\mathrm{mg} / \mathrm{kg}$ of the waste.

3.3.2.1 Technology Based Treatment Standards. Section 3004(m) of the Hazardous and Solid Waste Amendments requires EPA to promulgate treatment standards that reduce the toxicity or mobility of hazardous constituents so that short-and long-term threats to human health and the environment are minimized. To implement this mandate EPA chose to base treatment standards on technical practicability instead of risk assessment. Of all the proven, available technologies, the one that best minimizes the mobility and/or toxicity of hazardous constituents is designated as the BDAT for that waste. Definition of BDAT is based on EPA research into demonstrated and available treatment technologies. EPA then establishes a waste-code specific treatment standard based on the performance of the BDAT. These treatment standards are expressed as either concentration levels or required technologies.

Since the physical and chemical composition of a waste significantly impacts the effectiveness of a given treatment technology, EPA divided the treatment standard for each waste code into two categories: wastewaters and nonwastewaters. The Agency defines these two categories based on the percentages of total organic carbon (TOC) and total suspended solids (TSS) present in a waste (Section 268.2), since these factors commonly impact the effectiveness of treatment methods. Wastewaters are defined as wastes that contain less than $1 \%$ by weight total organic carbon (TOC) and less than $1 \%$ by weight total suspended solids (TSS). Nonwastewaters are wastes that do not meet the criteria for wastewaters.

The required performance of treatment processes for BDAT is based on the concentration of specific constituents in treatment residuals in the land disposal environment. In addition to establishing BDAT standards for both the wastewater and nonwastewater forms of a waste code, EPA will often set a standard for waste subgroups called "waste treatability groups" which consist of wastes with similar physical and chemical properties. EPA then determines what the demonstrated treatment technologies are for each "treatability group." To be considered a demonstrated treatment technology, a full-scale facility should be in operation for the waste or similar wastes. EPA then evaluates whether or not the particular demonstrated treatment technology is available.

To be considered available, a treatment technology must meet the following criteria:

1. The process may be available for purchase or lease, if the technology is proprietary or a patented process.

2. The technology must substantially reduce waste toxicity or substantially reduce the migration of hazardous constituents from the waste.

Once a treatment technology has been demonstrated and is available, EPA collects and analyzes performance data from the specific treatment. EPA then analyzes how each treatment technology substantially diminishes the toxicity of the waste or substantially reduces the likelihood of migration of hazardous constituents from the waste. Finally, EPA chooses the "best" treatment technology based on performance data (e.g., the levels to which the technologies can treat specific hazardous constituents in the waste), and sets a performance standard based on this specific technology. Where constituent specific performance data cannot be obtained or is deemed unnecessary, EPA considers specifying that a technology must be used for the waste. 
In some cases, the specific technologies identified as the basis for BDAT are simply those technologies that EPA used to develop the waste-specific performance standard. Any technology or combination of technologies not otherwise prohibited can be used to achieve these standards. In other words, a specific treatment technology does not have to be used unless the specific method of treatment is specified as the treatment standard.

When a treatment standard is a required technology, that technology must be used, unless it can be demonstrated that an alternative method can achieve a level of performance equivalent to the required technology.

Section 268.40 prescribes treatment standards expressed as specified technologies for certain wastes. These wastes must be treated using the specified technology. Table 1 in Section 268.42 provides full descriptions that elaborate on the five letter codes used in Section 268.40. Examples include incineration (NNCIN), fuel substitution (FSUBS), and mercury retorting (RMERC). In most cases, once treated by the required technology, wastes can be land-disposed without being tested. There are, however, some exceptions. For example, all F024 wastes must be incinerated. Following incineration, the remaining residues must then also meet the concentration levels specified in Section 268.40.

To date, EPA has set special treatment standards for four categories of mixed waste. They include:

1. Radioactive lead solids with a BDAT treatment standard of macroencapsulation

2. Radioactive elemental mercury with a BDAT treatment standard of amalgamation

3. Radioactive hydraulic oil contaminated with mercury and a BDAT treatment standard of incineration

4. Radioactive high-level wastes generated during the reprocessing of fuel rods with a BDAT standard of vitrification.

The remaining mixed wastes are subject to those promulgated treatment standards that apply to the hazardous portion of the waste unless EPA publishes specific standards for mixed waste treatability groups in the future. (For further discussion on mixed waste treatment standards see 55 FR 22532 and 22626, June 1, 1990.)

Under the LDRs, dilution is prohibited as treatment for both listed and characteristic wastes (see 40 CFR 268.3). However, exceptions to the prohibition were made for:

1. Certain characteristic wastes generated and managed in waste treatment systems regulated by the Clean Water Act (See 40 CFR 268.3(b)). (Note that prohibited wastes treated by inappropriate methods are considered impermissibly diluted.)

2. Listed and characteristic wastes that are aggregated for legitimate treatment in centralized treatment systems. (Note that centralized treatment of incompatible waste streams is not considered legitimate treatment and is viewed as impermissible dilution.)

3. Characteristic wastes that are disposed into hazardous or nonhazardous Class I injection wells regulated under the Safe Drinking Water Act and do not exhibit any prohibited characteristic of hazardous waste at the point of injection. 
4. Prohibited nontoxic ignitable, reactive, and corrosive wastes that are treated by dilution to meet a treatment standard.

3.3.2.2 Concentration Based Standards. When treatment standards are set as concentration levels, treatment is not limited to the BDAT used to establish the treatment standard; instead the Agency uses BDAT to determine what is the appropriate level of treatment for each hazardous constituent commonly found in the waste. The regulated community may then use any method or technology (except for impermissible dilution) to meet the treatment standard. After treatment, waste analysis or application of knowledge must be used to determine if the applicable concentration-based standards in Section 268.40 have been met.

Numeric standards are commonly expressed in $\mathrm{mg} / \mathrm{kg}$ when the BDAT is a destruction or extraction technology such as incineration. Compliance with these treatment standards is measured by analyzing a representative sample of the waste for the total concentration of each hazardous constituent identified in the treatment standard, and comparing it to the level given for the waste code.

Treatment standards given in $\mathrm{mg} / \mathrm{L}$ are also concentration-based standards. In wastewaters, compliance is demonstrated by comparing the concentration of hazardous constituents found in a composite sample of the waste with the regulatory level. For nonwastewaters, an extract that reflects the potential of hazardous constituents to leach from the waste must first be prepared. The waste meets the treatment standard if the concentrations of regulated constituents in the liquid extract are below the regulatory levels given for the waste code. EPA requires the use of the TCLP to obtain the waste extract.

3.3.2.3 Universal Treatment Standards. Use of BDAT to set treatment standards for hazardous wastes gave rise to an unintended consequence: the numeric treatment standard applied to an individual hazardous constituent, like benzene, could vary depending on the performance of the BDAT on each listed or characteristic wastestream that was evaluated. For example, nonwastewater forms of the listed wastes F005 and U019 both require treatment for benzene; however, the treatment standard originally set for benzene in the spent solvent was $3.7 \mathrm{mg} / \mathrm{kg}$, while the standard originally set for unused, discarded benzene was $36 \mathrm{mg} / \mathrm{kg}$.

To simplify the LDR program and eliminate this lack of consistency between standards, the Agency examined the range of numeric standards applied to each hazardous constituent found in restricted hazardous wastes. Based on the range, EPA assigned a single numeric value to each constituent for its respective wastewater and nonwastewater forms. A consolidated list of each constituent and its treatment standards (wastewater and nonwastewater) can be found in Section 268.48 and is known as the universal treatment standards (UTS). The values assigned to hazardous constituents in the UTS were then used to adjust numeric levels found in the treatment standards table of Section 268.40. Applying these universal treatment standards has not changed the hazardous constituents that must be treated in a particular waste, as only the numeric standards were amended. As a result, a common constituent found in multiple, different wastes will carry the same numeric treatment level. The treatment standards found in Section 268.40 for F005 and U019 nonwastewaters, therefore, continue to address benzene, but the level for each has been adjusted to $10 \mathrm{mg} / \mathrm{kg}$.

3.3.2.4 Characteristic Hazardous Waste. Just like listed wastes, restricted characteristic wastes must also meet treatment standards before they are eligible for land disposal. Since the land disposal restrictions attach at the point of generation, treatment standards applicable to characteristic wastes cannot be circumvented by simply removing the characteristic. Once a.waste is both decharacterized and treated to meet standards that applied at the point of generation, however, the waste may be land disposed in a nonhazardous, RCRA Subtitle D landfill. 
Special requirements have been established regarding wastes that exhibit a characteristic (Section 268.9). As a general principle, a hazardous waste must meet all applicable treatment standards to be eligible for land disposal. For purposes of LDR, a generator with a listed hazardous waste must determine if the waste also exhibits any hazardous waste characteristics (Section 262.11(c)). If the listed waste exhibits a characteristic of hazardous waste, the treatment standard for both waste codes must be met. An exception occurs, however, when the treatment standard for the listed waste specifically includes a standard for the constituent that causes the waste to exhibit the characteristic. In that case, compliance with the treatment standard for the listed waste will satisfy both requirements, as the standard for the listed waste will operate in lieu of the treatment standard for the characteristic waste code.

\subsubsection{Debris Rule}

Debris is defined by EPA as solid material exceeding $60-\mathrm{mm}$ particle size that is intended for disposal and that is: (1) manufactured object, (2) plant or animal matter, or (3) natural geologic material. Further, any mixture where the debris portion comprises the largest amount of material present by volume as determined by visual inspection is classified as debris.

Debris contaminated with hazardous material must be treated before land disposal as follows unless EPA determines under $40 \mathrm{CFR}$ 261.3(e)(2) that the debris is no longer contaminated with hazardous waste or the debris is treated to the waste-specific treatment standard for the waste contaminating the debris:

(1) General. Hazardous debris must be treated for each "contaminant subject to treatment" using the technology or technologies identified in Table 1 of 40 CFR 268.45. Contaminants subject to treatment include those that exhibit the toxicity characteristic, debris that is contaminated with a prohibited listed hazardous waste, or debris that is reactive because of cyanide.

(2) Characteristic debris. Hazardous debris that exhibits the characteristic of ignitability, corrosivity must be deactivated by treatment using one of the technologies identified in Table 1 of 40 CFR 268.45 .

(3) Mixtures of debris types. The treatment standards of Table 1 of 40 CFR 268.45 must be achieved for each type of debris contained in a mixture of debris types. If an immobilization technology is used in a treatment train, it must be the last treatment technology used.

(4) Mixtures of contaminant types. Debris that is contaminated with two or more contaminants subject to treatment must be treated for each contaminant using one or more treatment technologies identified in Table 1 of 40 CFR 268.45. If an immobilization technology is used in a treatment train, it must be the last treatment technology used.

(5) Waste PCBs. Hazardous debris that is also a waste PCB under 40 CFR part 761 is subject to the requirements of either $40 \mathrm{CFR}$ part 761 or the requirements of 40 CFR 268.45, whichever are more stringent.

Hazardous debris that has been treated using one of the specified extraction or destruction technologies in Table 1 of 40 CFR 268.45, and that does not exhibit a characteristic of hazardous waste after treatment, is no longer considered a hazardous waste and need not be managed in a Subtitle $C$ facility. Hazardous debris contaminated with a listed waste that is treated by an immobilization 
technology specified in Table 1 of 40 CFR 268.45 is a hazardous waste and must be managed in a Subtitle $C$ facility. Treatment residuals must be separated from the treated debris and are subject to the waste-specific treatment standards provided by Subpart D of 40 CFR 268.

\subsection{Hazardous Waste Identification Rules}

EPA has proposed two rules, known as the Hazardous Waste Identification Rules (HWIR), which could significantly impact the RCRA hazardous waste identification regulations. One HWIR proposal addresses as-generated waste (HWIR-waste, proposed in November 1995), and the other addresses contaminated media (HWIR-media, final in November 1998). Both proposals add flexibility to the hazardous waste identification system by providing a regulatory mechanism for certain hazardous wastes with low concentrations of hazardous constituents to exit the Subtitle C regulated universe.

The HWIR-waste rule addresses the inflexibility of the hazardous waste listings and the mixture and derived-from rules for as-generated wastes. Currently, with only a few exceptions, a listed waste remains a listed waste, even if it contains very low levels of hazardous constituents, is mixed with large volumes of solid wastes, or is treated to remove hazardous constituents. Such wastes are subject to extensive RCRA regulation, even though they may pose very little threat to human health and the environment. HWIR-waste will propose "exit levels" for each of the hazardous constituents in listed wastes. These levels will be generated by accounting for each constituent's toxicity and ability to migrate in the environment. If the concentrations of hazardous constituents in a waste are below the exit levels, then the waste will no longer carry a listing, and will no longer be hazardous (provided it exhibits no characteristics).

The application of existing Subtitle $C$ requirements to contaminated media and other remediation wastes often impedes cleanups because the Subtitle $C$ requirements impose unnecessary costs and limit cleanup options. HWIR-media addresses these problems by codifying the contained-in policy for environmental media and establishing exit levels (which are different than the exit levels established in HWIR-waste). As proposed by HWIR-media, contaminated media that meet the exit criteria and are generated by remediation activities being overseen by the EPA or a state agency will no longer be considered to contain hazardous waste, and will not be subject to further Subtitle $\mathrm{C}$ regulation. Note that the media must be generated as part of a cleanup overseen by the EPA or a state to be eligible for this exclusion. Even after the medium is no longer considered to contain hazardous waste and is excluded from Subtitle $\mathrm{C}$ regulation, it may still be subject to site-specific regulation by the overseeing agency.

To address various concerns, EPA will repropose the HWIR-Waste rule by October 31, 1999, and finalize the rule by April 30, 2001. HWIR-Media went final and is described in Federal Register / Vol. 63, No. 229 / Monday, November 30, 1998, pp. 65874-65947. This rule will become effective June 1, 1999.

\subsection{NRC Regulations}

NRC's mission, under the Atomic Energy Act of 1954 (AEA), as amended, is to regulate the nation's civilian use of by-product, source, and special nuclear materials to ensure adequate protection of public health and safety, to promote the common defense and security, and to protect the environment. The NRC's scope of responsibility includes regulation of commercial nuclear power plants; research, test, and training reactors; fuel cycle facilities; medical, academic, and industrial uses of nuclear materials; and the transport (along with the Department of Transportation), storage, and disposal of nuclear materials and wastes. NRC is authorized by the AEA to issue licenses to commercial users of source, special nuclear and by-product radioactive materials and to regulate federal facilities other than DOE and Naval Nuclear Propulsion Program facilities. 
Thirty states have signed agreements with the NRC enabling the various Agreement States to regulate source, by-product, and small quantities of special nuclear material within their boundaries. Facilities located in Agreement States are subject to regulatory requirements for radioactive material that are authorized by state law. This applies to all source, special nuclear, and by-product material, except that from utilization facilities and fuel cycle facilities, which are subject to NRC's requirements, and DOE facilities, which are subject to DOE orders. While Agreement States are required to adopt programs that are adequate to protect public health and safety and be compatible with the NRC program, Agreement States may also adopt some requirements that are more stringent than the comparable Federal $\mathrm{NRC}$ requirements. NRC retains authority over production and utilization facilities and other activities in Agreement States specified by section 274(c) of the AEA.

A large portion of the radioactive mixed waste generated by medical and biomedical research institutions contains radionuclides with relatively short half-lives. These short-lived radionuclides are especially prevalent in the combustible dry wastes, and aqueous wastes generated by medical and academic institutions. Currently, NRC generally allows medical facilities to store for decay. For example, generators may store waste containing radionuclides with half-lives of less than 65 days until the radiation emitted from the unshielded surface of the waste, as measured with an appropriate survey instrument, meets the decay levels described in their NRC license (typically 10 half-lives of decay and radioactivity levels indistinguishable from background levels). The waste may then be disposed as a nonradioactive waste after ensuring that all radioactive material labels are rendered unrecognizable (10 CFR 35.92). Radioactive waste may also be stored for decay under certain other circumstances in accordance with 10 CFR 20.2001. Such management can reduce worker exposure and potential risks to the public during transportation of the waste.

Generators of mixed waste must obtain a license from NRC or an NRC Agreement State for possession and use of radioactive materials, and may need a RCRA permit depending on the time waste is stored and the volume of waste generated. Some of the mixed waste generated by private entities and government (for example, wastes with radionuclide concentrations exceeding the acceptance criteria of commercial sector treatment and disposal facilities) is (and has been) stored onsite indefinitely. 


\section{MIXED WASTE TREATMENT OPTIONS}

To understand the complexity of the challenge involved with treating MLLW, it is important to define the wastes requiring treatment and their characteristics. Mixed waste varies greatly in terms of its chemical composition, physical form, quantity, and radioactive and hazardous components. The appropriate treatment for a specific mixed waste depends on these variables. Mixed wastes may be grouped together into "treatability groups," which have similar characteristics. Mixed waste treatment focuses primarily on treating the hazardous component of the waste to LDR standards, which can be accomplished through a variety of processes such as:

- Wastewater treatment (neutralization, filtration, evaporation)

- Stabilization (solidifying the waste)

- Organic destruction (destroying organic liquids or solids by thermal destruction or use of non-thermal processes such as chemical oxidation)

- Effecting chemical changes in the waste (such as changing the $\mathrm{pH}$ of a waste, using a precipitation process to remove one component of the waste)

- Other physical processes (such as encapsulation or separation).

Some of the treatment options can be used effectively only on certain waste streams, others may be only one step in a series of treatments that are combined to provide the necessary treatment. Any residuals remaining after treatment must be stored or disposed of in accordance with NRC and RCRA requirements.

Use of commercial vendors to varying degrees may be an appropriate treatment or disposal option. Other options include hiring a commercial vendor to come onsite with treatment equipment (such as mobile or transportable treatment units) to treat the generator's waste, or contracting a private company to come onsite to build and operate a treatment facility.

Extremely small volumes of mixed waste (a total of approximately 1 cubic meter, or about 5.5 drums) may be treated by conducting treatability studies at a research or laboratory facility. The goal of these studies is to provide the scientific research necessary to support the development and design of new treatment technologies. These studies will yield information about the appropriate types of treatment conditions required for treatment, residuals that remain after treatment, and other characteristics of the technology.

\subsection{Treatment Methods}

Mixed waste consists of a variety of waste matrices and contaminants. Typical waste streams by waste matrix are identified in Table 1. Each matrix is followed by example descriptions of the wastes that fall into that category. The appropriate treatment technology or treatment process will depend on the waste matrix and the contaminants. Most MLLW treatment methods are based on methods used for treatment of the hazardous waste components to LDR standards with additional requirements for containment of the radioactive component and minimization of exposure. 
Table 1. Waste Matrix Categories

1. Aqueous Liquids and Slurries

- Wastewaters and aqueous slurries

- Acidic wastewaters and aqueous slurries

- Basic wastewaters and aqueous slurries

- Cyanide wastewaters

\section{Organic Liquids}

- Aqueous/organic liquids

- Aqueous/halogenated organic liquids

- Aqueous/Nonhalogenated Organic Liquids

- Pure organic liquids

- Halogenated pure organic liquids

- Nonhalogenated pure organic liquids

- PCBs

3. Solid Process Residues

- Inorganic particulates

- Ash

- $\quad$ Sand blasting media

- Absorbed aqueous liquids

- Absorbed organic liquids

- Ion exchange media

- Calcined solids

- Inorganic sludges

- Wastewater treatment sludges

- $\quad$ Plating waste sludges

- Paint waste-liquids/sludges 
Table 1. (Continued)

- Paint waste-chips/solids

- RCRA metal salt wastes

- Organic process residues

- Activated carbon (halogenated or nonhalogenated)

- Organic resins (halogenated or nonhalogenated)

- Organic absorbents (halogenated or nonhalogenated)

- Organic sludges (halogenated or nonhalogenated)

- Organic particulates (halogenated or nonhalogenated)

- Biological materials

- Organic chemicals (halogenated or nonhalogenated)

4. Soils

- Organic contaminated soils (halogenated or nonhalogenated)

- RCRA metal contaminated soils

- Contaminated soils/debris

5. Debris Waste

- Metal debris with RCRA/TSCA contamination

- Concrete

- Glass

- Ceramic/brick

- Asbestos

- Combustible

- Plastic/rubber (halogenated or nonhalogenated)

- Wood

- Paper/cloth/trash

- Graphite

- Biological 
Table 1. (Continued)

- Composite filters

- Asphalt

6. Special Waste

- $\quad$ Reactive metals

- Components contaminated with reactive metals

- Pyrophoric fines

- $\quad$ Explosives/propellants

- Compressed gases/aerosols

7. Inherently Hazardous Waste

- Elemental mercury

- $\quad$ Elemental lead

- Beryllium

- Batteries

- Lead acid batteries

- Cadmium batteries.

Many waste treatment technologies have limits on feedstream chemical content, physical composition, and particle size. These constraints, coupled with the nature of the waste, dictate at least some degree of feed material sorting and separation. All treatment systems will require some form of sorting and segregation of the waste to prevent accidents, inadvertent releases, or equipment damage. For example, it is generally undesirable for materials such as bulk lead and mercury to enter a thermal treatment unit because they are particularly hazardous volatile materials that are difficult to collect in the offgas system. Thus, treatment facilities have Waste Acceptance Criteria (WAC) that specify acceptable waste characteristics, constituents, and contaminant concentration. Many technologies also require shredding (3.1.5) of the waste or other methods of size reducing (3.1) the waste components to produce an acceptable feedstock.

\subsubsection{Aqueous Liquids and Slurries}

These wastes may require treatment to remove or destroy the hazardous organic component or remove radionuclides and/or heavy metals for subsequent discharge under a National Pollutant Discharge Elimination System (NPDES) water discharge permit under the Clean Water Act of 1977. Typically, the following technologies would be in a treatment train to remove contaminants in the wastewater to required concentration limits before discharge. 
Treatment methods to remove insoluble particles or organic contaminants may include filtration (3.3) (cartridge filters (3.3.1.1), granular bed filtration (3.3.5), microfiltration, ultrafiltration (3.3.4, etc.) or centrifugation (3.6.5). Steam stripping (3.6.9) may be applicable to wastewaters that contain organics that are sufficiently volatile for removal by steam application. Evaporation (3.5) may be used to separate the aqueous phase from insoluble or soluble inorganics. However, highly volatile radionuclides and heavy metals, such as iodine, boron, tritium, and mercury may be difficult to separate from the evaporated water stream.

Soluble organics may be removed from the aqueous matrix by activated carbon (3.6.3) beds or by organic destruction. Destruction of organics in an aqueous matrix may be accomplished by supercritical water oxidation (3.11.6), ultraviolet (UV) photo-oxidation, electrochemical oxidation using either $\mathrm{Ag}^{+2}$ or $\mathrm{Ce}^{+4}$ as the oxidizer, or wet oxidation.

Radionuclides or heavy metals may be removed from the aqueous waste by precipitation (3.6.4), ion exchange (3.6.2), electrodialysis (3.3.3), reverse osmosis (3.6.1), or chelating agents and subsequent filtration or magnetic separation.

Cyanide may be treated for destruction by oxidation/reduction (3.11.2) reactions with hydrogen peroxide or ozone, or alkaline chlorination. Neutralization (3.11.1) may be applied to acidic or basic waste streams.

Liquid waste may also be sorbed into some type of absorption media (paper towel, diaper, etc.) and treated as a solid process residue. Filter sludges, evaporator bottoms, spent ion exchange resins, and activated carbon beds are also treated as solid process residue.

\subsubsection{Organic Liquids}

As with aqueous waste, organic liquids may be sorbed into a solid absorption media and subsequently treated as process solids. Other methods of treating organic liquids include thermal or nonthermal destruction of the organic liquid (e.g., conversion to $\mathrm{CO}_{2}$, water, inorganic salts, and low molecular weight organics).

Thermal methods of organic destruction include incineration (3.7), plasma torch, graphite electrode DC arc furnace, supercritical water oxidation (3.11.6), steam reforming (3.11.4), molten salt oxidation, and metal melting (3.11.7). Gas phase reduction (Eco Logic Process) of organics would require vaporization of the organic for reduction to methane and water in the gas phase. Incineration is a mature and proven technology that has generally been the primary choice of industry for destroying hazardous waste. The technical risks are low and the costs are well-established. However, public opposition to incineration and several other thermal treatment technologies is established and growing due to perceived problems associated with high volumes of offgas and the carryover and volatilization of contaminants into the offgas.

Nonthermal waste-treatment technologies typically destroy organics in a liquid medium. Although these processes may operate at elevated temperatures and pressures, the driving force is chemical rather then thermal. Thus, these processes do not exhibit the large quantities of offgas generally associated with thermal treatment processes. However, these technologies are immature and have not been fully demonstrated and implemented in a variety of waste treatment applications. These technologies include acid digestion, direct chemical oxidation (DCO), electrochemical oxidation, and catalytic chemical oxidation. 


\subsubsection{Solid Process Residues}

Treatment of solid process residues will depend on the character of the solid matrix and the type of contaminant. Organic solids may be treated by most of the thermal or nonthermal treatment technologies identified for organic liquids. However, for many of these processes, the solids will require significant size reduction. The selection of the technology may be more dependent on the contaminant than on the solid matrix. For example, trash is easily burned in an incinerator. However, if the trash is contaminated with mercury it may be more expedient to shred the trash and treat it in a lower temperature steam reformer or nonthermal process than to remove mercury from the offgas stream.

Many inorganic solids contaminated with hazardous organics may also be treated by most thermal processes mentioned above. As with the plasma torch and DC arc, a Joule-heated melter (3.8.1) or microwave-heated melter (3.8.2) may be used to treat these solids by oxidizing the organic contaminant and vitrifying the solid in one operation. Again, size of the solids is an issue.

In lieu of direct thermal treatment, organic or inorganic contaminants may be separated from the solid matrix. Separation processes include thermal desorption (3.11.8), washing (3.11.3) or leaching, and supercritical carbon dioxide extraction. This may be appropriate as a pretreatment to meet WAC requirements or to minimize volatilized contaminants in the offgas of a thermal treatment process.

In some cases, depending on the contaminants and level of contamination, the solids may be directly stabilized and disposed of without prior treatment. In addition to vitrification, several nonthermal stabilization processes exist including:

- Chemically bonded phosphate ceramic (CBPC)

- Grout or Portland Cement (3.9.1)

- $\quad$ Polymer microencapsulation (3.9.2) by extrusion (PME)

- $\quad$ Polymer microencapsulation by kinetic mixing (PMK)

- Enhanced cement for high salt content, mixed wastes

- Sol-gel to stabilize high salt content mixed waste

- Polysiloxane based material binder for high salt content mixed wastes

- $\quad$ Sintering for stabilizing fly ash from mixed waste

- MAECTTTE

- Mercury stabilization (De-Merc process).

\subsubsection{Soils}

Soils are inorganic solids and can be treated by the processes described above.

\subsubsection{Debris}

As with other waste streams, debris contaminated with listed hazardous wastes (either on the debris surface or in its interstices, such as pore structure) or debris that exhibits a characteristic hazard is subject to the LDR BDAT. Unlike the other wastes, debris may be treated to the alternative treatment standards 
before land disposal. Seventeen alternative treatment technologies are specified under the categories of extraction, destruction, and immobilization. These technologies are identified in Table 2 of in 40 CFR 268.45, which is reproduced below. These seventeen technologies are identified by EPA as BDAT for hazardous debris. Treatment technologies for removing hazardous constituents from debris may be applicable to the removal of radioactive contamination; however, the process parameters and contaminant removal criteria may differ.

\subsubsection{Special Waste}

Treatment and disposition of these waste streams will require highly specialized solutions for specific waste streams. Technologies are under development for a few of these waste categories, including base hydrolysis for explosives and propellants, and a gas recontainerization process for compressed gases and aerosols. Nonthermal chemical oxidation processes may also be applicable to destruction of explosives and propellants.

\subsubsection{Inherently Hazardous Waste}

Inherently hazardous waste generally requires surface decontamination, liquid separation where required, and encapsulation.

The BDAT for elemental mercury is amalgamation. Although there is currently no commercially available process, two elemental mercury amalgamation systems have been developed: (1) $\mathrm{DeHg}^{\mathrm{SM}}$ process for Mercury-Bearing Waste Treatment by Nuclear Fuel Services, and (2) the Liquid Elemental Mercury Amalgamation Treatment System for Mercury-Bearing Waste Treatment by ADA Technologies.

Soils and sludges containing less than $260 \mathrm{ppm}$ of mercury require a waste stabilization process to prevent from releasing mercury into the environment.

Commercial stabilization capabilities for $<260 \mathrm{ppm}$ mercury contaminated wastes are being investigated by DOE's Mixed Waste Focus Area (MWFA) and demonstrations have been completed by four vendors.

Current regulations for wastes contaminated at $>260-\mathrm{ppm} \mathrm{Hg}$ allows only incineration, if organics requiring incineration are present, or roasting/retorting. Stabilization and thermal desorption processes for $>260$-ppm Hg wastes are being investigated by the MWFA. Nonthermal mercury treatment technologies will be compared against a currently EPA-required retort process in treatment demonstrations and a new waste form evaluation procedure from the EPA will be used to test the final waste forms. Sepra Dyne Corp. will demonstrate its vacuum retort, which will serve as the baseline for comparison. Brookhaven National Laboratory will use sulfur polymer cement, International Technologies will use a grout-based process, and Nuclear Fuel Services will demonstrate its DeHg process.

Specialty sorbents with high capacity for mercury are also being investigated for recovery of mercury from liquids. A regenerable sorbent that is specific for mercury has been developed by ADA Technology to separate mercury from water and aqueous solutions. The sorbent would be thermally regenerated to recover mercury that would then be recycled or stabilized for disposal. ADA has also recently developed new low-cost sorbents and a new filter that simultaneously sorbs the soluble mercury fraction while it removes the particulate-bound mercury.

Self-Assembled Mesoporous Mercaptan Support (SAMMS) material is being investigated by the MWFA as a mercury sorbent to separate mercury-bearing waste from organic liquid waste matrices. 
Another process involving sonic agitation with peroxide and polymer reaction and filtration is being tested to remove mercury from organic liquids. 
Table 2. Alternative treatment standards for hazardous debris. ${ }^{1}$

Performance and/or design and operating

Technology description

$$
\text { standard }
$$

Contaminant restrictions ${ }^{2}$

\section{A. Extraction Technologies:}

\section{Physical Extraction (3.4.1)}

a. Abrasive Blasting: Removal of contaminated debris surface layers using water and/or air pressure to propel a solid media (e.g., steel shot, aluminum oxide grit, plastic beads).

\section{b. Scarification, Grinding, and Planing:}

Processes using striking piston heads, saws, or rotating grinding wheels such that contaminated debris surface layers are removed.

c. Spalling: Drilling or chipping holes at appropriate locations and depth in the contaminated debris surface and applying a tool which exerts a force on the sides of those holes such that the surface layer is removed.

The surface layer removed remains hazardous debris subject to the debris treatment standards.

d. Vibratory Finishing: Process using scrubbing media, flushing fluid, and oscillating energy such that hazardous contaminants or contaminated debris surface layers are removed. ${ }^{4}$

\section{e. High Pressure Steam and Water}

Sprays: Application of water or steam sprays of sufficient temperature, pressure, residence
Glass, metal, plastic, and rubber: Treatment to a clean debris surface. ${ }^{3}$

Brick, cloth, concrete, paper, pavement, rock, and wood: Removal of at least $0.6 \mathrm{~cm}$ of the surface layer; treatment to a clean debris surface. $^{3}$

Same as above

Same as above

Same as above

Same as above

Same as above

Same as above
Same as above
All Debris: None. 
Table 2. (continued).

\begin{abstract}
Technology description
time, agitation, surfactants, and detergents to remove hazardous contaminants from debris surfaces or to remove contaminated debris surface layers.
\end{abstract}

\section{Chemical Extraction (3.4.2)}

a. Water Washing and Spraying:

Application of water sprays or water baths of sufficient temperature, pressure, residence time, agitation, surfactants, acids, bases, and detergents to remove hazardous contaminants from debris surfaces and surface pores or to remove contaminated debris surface layers.

b. Liquid Phase Solvent Extraction: Removal of hazardous contaminants from debris surfaces and surface pores by applying a nonaqueous liquid or liquid solution that causes the hazardous contaminants to enter the liquid phase and be flushed away from the debris along with the liquid or liquid solution while using appropriate agitation, temperature, and residence time.

c. Vapor Phase Solvent Extraction: Application of an organic vapor using sufficient agitation, residence time, and temperature to cause hazardous contaminants on contaminated debris surfaces and surface pores to enter the vapor phase and be flushed away with the organic vapor.
Performance and/or design and operating

standard

Contaminant restrictions ${ }^{2}$
All Debris: Treatment to a clean debris surface.

Brick, cloth, concrete, paper, pavement, rock, and wood: Debris must be no more than $1.2 \mathrm{~cm}(1 / 2 \mathrm{inch})$ in one dimension (i.e., thickness limit), ${ }^{5}$ except that this thickness limit may be waived under an "Equivalent Technology" approval under § 268.42(b); debris surfaces must be in contact with water solution for at least 15 minutes

Same as above

Same as above, except that brick, cloth, concrete, paper, pavement, rock and wood surfaces must be in contact with the organic vapor for at least 60 minutes.
Brick, cloth, concrete, paper, pavement, Rock, and Wood: Contaminant must be soluble to at least $5 \%$ by weight in water solution or $5 \%$ by weight in emulsion; if debris is contaminated with a dioxin-listed waste, 6 an "Equivalent Technology" approval under $\S 268.42(b)$ must be obtained.

Brick, Cloth, Concrete, Paper, Pavement, Rock, and Wood: Same as above, except that contaminant must be soluble to at least $5 \%$ by weight in the sol-vent.
Same as above 
Table 2. (continued).

Technology description

\section{Thermal Extraction}

a. High Temperature Metals Recovery

(3.10): Application of sufficient heat, residence time, mixing, fluxing agents, and/or carbon in a smelting, melting, or refining furnace to separate metals from debris.

b. Thermal Desorption (3.11.8): Heating in an enclosed chamber under either oxidizing or nonoxidizing atmospheres at sufficient temperature and residence time to vaporize hazardous contaminants from contaminated surfaces and surface pores and to remove the contaminants from the heating chamber in a gaseous exhaust gas.r

\section{B. Destruction technologies:}

1. Biological destruction

Biological destruction (Biodegradation): Removal of hazardous contaminants from debris surfaces and surface pores in an aqueous solution and biodegration of organic or non-metallic inorganic compounds (i.e., inorganics that contain phosphorus,

Performance and/or design and operating standard

Contaminant restrictions ${ }^{2}$

For refining furnaces, treated debris must be separated from treatment residuals using simple physical or mechanical means, ${ }^{9}$ and, prior to further treatment, such residuals must meet the waste-specific treatment standards for organic compounds in the waste contaminating the debris.

All Debris: Obtain an "Equivalent Technology" approval under $\$ 268.42$ (b); treated debris must be separated from treatment residuals using simple physical or mechanical means, ${ }^{9}$ and, before further treatment, such residue must meet the wastespecific treatment standards for organic compounds in the waste contaminating the debris.

Brick, cloth, concrete, paper, pavement, rock, and wood: Debris must be no more than 10 $\mathrm{cm}$ (4 inches) in one dimension (i.e., thickness limit), ${ }^{s}$ except that this thickness limit may be waived under the "Equivalent Technology" Approval

\section{All Debris: Obtain an "Equivalent} Technology" approval under $\$ 268.42(b){ }^{8}$ treated debris must be separated from treatment residuals using simple physical or mechanical means, ${ }^{9}$ and, before further
Debris contaminated with a dioxin-listed waste:" Obtain an "Equivalent Technology" approval under $\S 268.42(b)$.

All Debris: Metals other than mercury.
All Debris: Metal contaminants. 
Table 2. (continued).

Technology description

nitrogen, or sulfur) in units operated under either aerobic or anaerobic conditions.

\section{Chemical Destruction}

a. Chemical Oxidation (3.11.2): Chemical or electrolytic oxidation using the following oxidation reagents (or waste reagents) or combination of reagents:

(1) Hypochlorite (e.g., bleach)

(2) Chlorine

(3) Chlorine dioxide

(4) Ozone or UV (ultraviolet light) assisted ozone;

(5) peroxides; persulfates; perchlorates permanganates; and/or

(6) other oxidizing reagents of equivalent destruction efficiency. ${ }^{4}$

Chemical oxidation specifically includes what is referred to as alkaline chlorination.

b. Chemical Reduction (3.11.2): Chemical reaction using the following reducing reagents (or waste reagents) or
Performance and/or design and operating standard

Contaminant restrictions ${ }^{2}$

treatment, such residue must meet the waste-

specific treatment standards for organic

compounds in the waste contaminating the

debris.

Brick, cloth, concrete, paper, pavement, rock, and wood: Debris must be no more than

$1.2 \mathrm{~cm}(1 / 2 \mathrm{inch})$ in one dimension

(i.e., thickness limit), ${ }^{5}$ except that this thickness

limit may be waived under the "Equivalent

Technology" approval

\section{All Debris: Obtain an "Equivalent}

Technology" approval under $§ 268.42(b){ }^{8}$

treated debris must be separated from

treatment residuals using simple physical or mechanical means, ${ }^{9}$ and, before further

treatment, such residue must meet the wastespecific treatment standards for organic compounds in the waste contaminating the debris.

Brick, cloth, concrete, paper, pavement, rock, and wood: debris must be no more than $1.2 \mathrm{~cm}(1 / 2 \mathrm{inch})$ in one dimension (i.e., thickness limit), ${ }^{5}$ except that this thickness limit may be waived under the "Equivalent Technology" approval

\section{Same as above}

Same as above

All Debris: Metal contaminants. 
Table 2. (continued).

\author{
Technology description \\ combination of reagents: \\ (1) sulfur dioxide \\ (2) sodium, potassium, or alkali salts of \\ sulfites, bisulfites, and metabisulfites, \\ and polyethylene glycols (e.g., NaPEG \\ and KPEG) \\ (3) sodium hydrosulfide \\ (4) ferrous salts; or \\ (5) other reducing reagents of equivalent \\ efficiency. ${ }^{4}$
}

3. Thermal Destruction (3.11.8): Treatment in an incinerator operating in accordance with Subpart O of Parts 264 or 265 of this chapter; a boiler or industrial furnace operating in accordance with Subpart H of Part 266 of this chapter, or other thermal treatment unit operated in accordance with Subpart X, Part 264 of this chapter, or Subpart P,

Part 265 of this chapter, but excluding for purposes of these debris treatment standards Thermal Desorption units.

\section{Immobilization Technologies:}

1. Macroencapsulation (3.9.2): Application of surface coating materials such as polymeric organics (e.g., resins and plastics) or use of a jacket of inert in-organic materials to substantially reduce surface exposure to potential leaching media.

2. Microencapsulation (3.9.2): Stabilization of the debris with the following reagents

Performance and/or design and operating standard

Contaminant restrictions ${ }^{2}$

Treated debris must be separated from treatment residuals using simple physical or mechanical means, ${ }^{9}$ and, before further treatment, such residue must meet the wastespecific treatment standards for organic compounds in the waste contaminating the debris.

Encapsulating material must completely Encapsulate debris and be resistant to degradation by the debris and its contaminants and materials into which it may come into contact after placement (leachate, other waste, microbes).

Leachability of the hazardous contaminants must be reduced.
Brick, concrete, glass, metal, pavement, rock, and metal: metals other than mercury, except that there are no metal restrictions for vitrification.

Debris contaminated with a dioxin-listed waste. ${ }^{6}$

Obtain an "Equivalent Technology" approval under $\S 268.42(b){ }^{8}$ except that this requirement does not apply to vitrification.
None

None. 
Table 2. (continued).

Performance and/or design and operating

Technology description

standard

Contaminant restrictions ${ }^{2}$

(or waste reagents) such that the leachability

of the hazardous contaminants is reduced:

(1) Portland cement; or

(2) Limè/pozzolans (e.g., fly ash and cement . kiln dust).

Reagents (e.g., iron salts, silicates, and clays) may be added to enhance the set/ cure time and/or compressive strength, or to reduce the leachability of the hazardous constituents. ${ }^{5}$

3. Sealing: Application of an appropriate material that adheres tightly to the debris surface to avoid exposure of the surface to potential leaching media. When necessary to effectively seal the surface, sealing entails pretreatment of the debris surface to remove foreign matter and to clean and roughen the surface. Sealing materials include epoxy, silicone, and urethane compounds, but paint may not be used as a sealant.

Sealing must avoid exposure of the debris surface to potential leaching media and sealant must be resistant to degradation by the debris and its contaminants and materials into which it may come into contact after placement (leachate, other waste, and microbes).
None.

1. Hazardous debris must be treated by either these standards or the waste-specific treatment standards for the waste contaminating the debris. The treatment standards must be met for each type of debris contained in a mixture of debris types, unless the debris is converted into treatment residue as a result of the treatment process. Debris treatment residuals are subject to the waste-specific treatment standards for the waste contaminating the debris.

2. Contaminant restriction means that the technology is not BDAT for that contaminant. If debris containing a restricted contaminant is treated by the technology, the contaminant must be subsequently treated by a technology for which it is not restricted in order to be land disposed (and excluded from Subtitle C regulation).

3. Clean debris surface" means the surface, when viewed without magnification, shall be free of all visible contaminated soil and hazardous waste except that residual staining from soil and waste consisting of light shadows, slight streaks, or minor discolorations, and soil and waste in cracks, crevices, and pits may be present provided that such staining and waste and soil in cracks, crevices, and pits shall be limited to no more than $5 \%$ of each square inch of surface area. 
Table 2. (continued).

\section{Performance and/or design and operating}

standard

\section{Technology description}

\section{Contaminant restrictions ${ }^{2}$}

4. Acids, solvents, and chemical reagents may react with some debris and contaminants to form hazardous compounds. For example, acid washing of cyanide-contaminated debris could result in the formation of hydrogen cyanide. Some acids may also react violently with some debris and contaminants, depending on the concentration of the acid and the type of debris and contaminants. Debris treaters should refer to the safety precautions specified in Material Safety Data Sheets for various acids to avoid applying an incompatible acid to a particular debris/contaminant combination. For example, concentrated sulfuric acid may react violently with certain organic compounds, such as acrylonitrile.

5. If reducing the particle size of debris to meet the treatment standards results in material that no longer meets the $60 \mathrm{~mm}$ minimum particle size limit for debris, such material is subject to the waste-specific treatment standards for the waste contaminating the material, unless the debris has been cleaned and separated from contaminated soil and waste prior to size reduction. At a minimum, simple physical or mechanical means must be used to provide such cleaning and separation of nondebris materials to ensure that the debris surface is free of caked soil, waste, or other nondebris material.

6. Dioxin-listed wastes are EPA Hazardous Waste numbers FO20, FO21, FO22, FO23, FO26, and FO27.

7. Thermal desorption is distinguished from Thermal Destruction in that the primary purpose of Thermal Desorption is to volatilize contaminants and to remove them from the treatment chamber for subsequent destruction or other treatment.

8. The demonstration "Equivalent Technology" under $\$ 268.42$ (b) must document that the technology treats contaminants subject to treatment to a level equivalent to that required by the performance and design and operating standards for other technologies in this table such that residual levels of hazardous contaminants will not pose a hazard to human health and the environment absent management controls.

9. Any soil, waste, and other nondebris material that remains on the debris surface (or remains mixed with the debris) after treatment is considered a treatment residual that must be separated from the debris using, at a minimum, simple physical or mechanical means. Examples of simple physical or mechanical means are vibratory or trommel screening or water washing. The debris surface need not be cleaned to a "clean debris surface" as defined in Note 3 when separating treated debris from residue; rather, the surface must be free of caked soil, waste, or other nondebris material. Treatment residuals are subject to the waste-specific treatment standards for the waste contaminating the debris. 